\title{
IDENTIFICATION OF UNBALANCE SEVERITY THROUGH FREQUENCY RESPONSE FUNCTION AND ARTIFICIAL NEURAL NETWORKS
}

\author{
A. ABD EL NAEEM, NOUBY M. GHAZALY \& G. T. ABD EL- JABER
}

Department of Mechanical Engineering, Faculty of Engineering, South Valley University, Qena, Egypt

\begin{abstract}
Rotating equipment is the main production process player. The new industrial revolution aims to increase the running time and efficiency for the rotating equipment to maximize the profit and reduce maintenance costs through avoid or early predict and correct occurred faults like unbalance, looseness, misalignment, etc.. Mass unbalance represents $35 \%$ of common problems in rotating equipment by control unbalance problem a void the equipment deterioration and power losses. These lead to open a wide research in rotor dynamic challenges fields. This study proposed a new method to identify unbalance severity in the system under study with statistical features and the amplitude frequency domain. The generated ANN validate by the statistical features with the amplitude values which is used in the ANN test. Practical works on overhang rotor bearing system at $25 \mathrm{~Hz}$ and measure the output unbalance conditions of the rotor. Different features in statistical and spectrum are generated from the vibration and the neural network is created. It is found that the statistical features results are better than the frequency domain amplitudes. ANNs are used to identify the unbalance severity and the method will help in predict faults and arrange best maintenance action.
\end{abstract}

KEYWORDS: Unbalance, Frequency Response Function, Rotating Machines, Vibration, Artificial Neural, Networks

Received: Jun 08, 2020; Accepted: Jun 28, 2020; Published: Sep 08, 2020; Paper Id.: IJMPERDJUN20201115

\section{INTRODUCTION}

All industrial applications consist of many rotating equipment. The main causes of mechanical failures are due to vibrations which is the main symptoms of rotating machinery problems. Failures of rotating machinery lead to economic losses such as maintenance cost and production losses. One of the main techniques in faults detection is vibration analysis where it can cover around $60 \%$ of common problems. (Lei Y. 2008) introduced a technique for rotating machinery smart fault diagnoses depends on adaptive neurofuzzy interface system (ANFIS). Their proposed approach was applied successfully in elasto-hydrodynamic rolling element bearings in fault diagnosis. The testing results showed that the proposed approach gives a strong detection tool of abnormalities in bearings and define the category the severity of faults. Moreover, the proposed feature effectiveness of the selected method clarified in the testing results. The main rotating machines faults are: rotors unbalance, misalignment, looseness, bearing problems, etc. Faults have specific characteristics behavior on the system vibration response. Between all rotating machines problems which can be detected by vibration unbalance with its different types represent $35 \%$ of expected problem as it's sensitive to any mass or thermal change in the rotating parts. Hence, it's important to keep system at designed efficiency to avoid or keep normal operation away from any unbalance. The reasons of mass unbalance are different as discussed some of them are manufacturing errors, materials built up or loss during normal operations, porosity in castings, and manufacturing tolerances. 
Previous researches has been introduced a wide range of methods in the process of unbalance identification and modeling response. (D. 1989) Used a modal procedure to define unbalance response of the system to compute the rotors unbalance response the system modelled as a multi degree of freedom using finite elements. By neglecting the system damping the solving sequence got easier and similar to followed in fixed structure. The same steps can be followed on damped systems considering that the damping distribution cannot proportion ally using this advantage and be cost effective for the computational analysis of natural and non-natural systems. (S. 2005)worked on a new model which depends on the direct detection of rotor unbalance and test a simulation process in case of rotor unbalance acting. The induced fault results of the rotor system consider the equivalent system loads in the mathematical model and the final results indicate that the fault size and location have been identified while the symptoms of the faults are calculated using fast Fourier transform. Using vibration as a monitoring tool will helps in detect complex problems at different operating condition because the uncertainty shown the fault initiation and machine operating parameters.

(Sanz J. 2007) introduced wavelet transforms and auto-associative neural networks way to fault identification. The suggested method to detect the fault symptom by using the difference between input of wavelet coefficients and output network. Moreover, they use DWT to generate novelty index vector which was different from the followed in the scalar indexes and open the way to define of frequency and time at which the faults appear. That helps to be a tool to localize the faults such as broken tooth. ( $\mathrm{Li} 2000$ ) presented a new approach to diagnosis the rolling bearings faults by the neural network and time frequency domain in the process of bearing vibration analysis. The developed vibration simulation model was used in define various faults diagnosis strategies of rolling bearing. The comparison between actual and simulation testing results reached that neural networks were an effective method for various bearing faults through interpretation of motor vibration readings signatures.

A perceptron pattern multi-layer classifier dedicated for interpretation of wavelet map with its application as mechanical fault localization tool is developed by (Chen 2002). First, a scale distribution was presented to quantify pattern features instead of inspection of complex wavelet patterns in time domains avoiding the limitation of availability and human experience by automatic faults feature classification. (Kankar P. K. 2014)worked on a multiscale permutation entropy to diagnosis the ball bearings faults connected to fault feature selection. Based on statistical parameters and permutation entropy the classification of faults as features in the process of supervised and unsupervised machine learning methods like artificial neural networking, self-organizing maps and a support vector machine.

The dynamic behavior of direct coupled system was examined by (Taplak 2012).The practical measurements in vertical direction were implemented and the vibration trend analysis and spectrum were used in define the high vibration sources. The results indicated that rotating machines had one or more vibration source and trend the vibration pattern in time wave form or spectrum analysis were effective tools in faults diagnosis of rotating mechanical systems. (Sinha J. K. and Elbhbah 2012) a way to define the optimum bearing housing vibration measuring sensors trough improving the mathematical works. The concept was to collect and fusion of all output signal in frequency domain to reach the machine composite. (Wang C. C. 2010) studied the autoregressive coefficients at different values were used as a learning samples for the neural network back propagation and define the fault types. (Kalkat M. 2005) investigate a neural network predictor to analyzing the rotating system vibration parameters such as amplitude and $\mathrm{v}$ frequency were measured on the bearing. The new neural network had input, hidden and output layers. The results would be used to analysis and predict in vibration measuring directions. 
In this study,vthe proposed a new method to identify unbalance severity in the system under study with statistical features and the amplitude frequency domain is conducted. The generated ANN validate by the statistical features with the amplitude values which is considered in the ANN test. Practical works on overhang rotor bearing system at $25 \mathrm{~Hz}$ and measure the output unbalance conditions of the rotor. Several features in statistical and spectrum are generated from the vibration and the neural network is created.

\section{Description of Balancing Test Rig}

In order to evaluate proposed balancing technique, the experimental studies were executed on a mass unbalancing simulator. The components were three phase $1.1 \mathrm{Kw}$ induction motor, two rollers bearing, flexible couplings, rotor and mass unbalance weights, as it appeared in Figure 1. The balancing rotor was overhang impeller which was a widely used in industry. The structure of the supporting frame was $\mathrm{C}$ section under the motor and unbalance plane which were fixed on a heavy multifunction table bed. The mechanical rotation motion of the AC motor was transferred directly to the shaft of the balancing rotor through flexible coupling. More details about the descriptions of the test rig facility is explained by Ahmed et al. (2019).

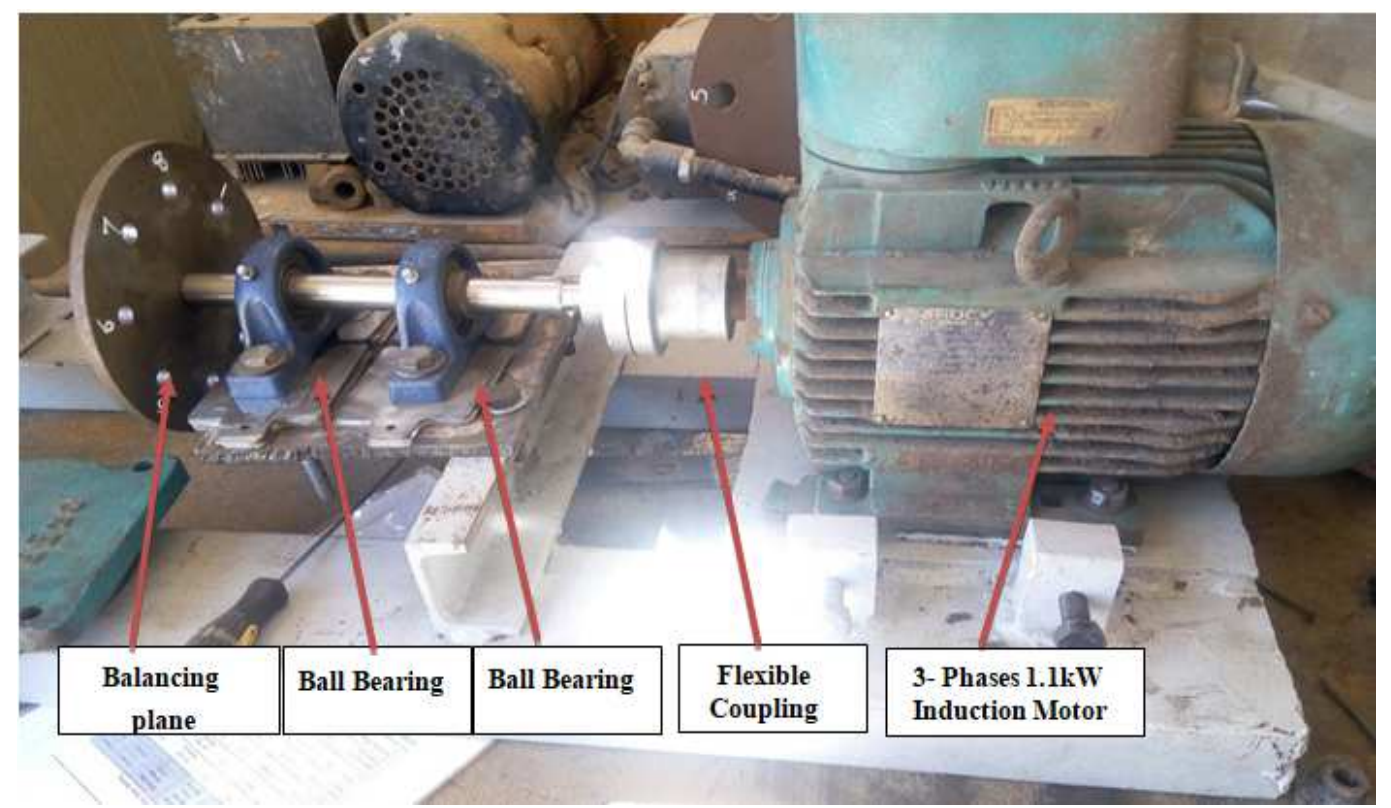

Figure 1: Experimental Test Rig with Single Overhang Balancing Plane.

\section{Vibration Measuring and Analysis Kits}

A piezo-electric tri-axial accelerometer PCB model 338C04 which was a common transducer in vibration measurements. The main advantages for these sensors are strong signals accuracy in a large frequency ranges to collect accurate vibrations signals from various sources like low speed shafts which equal fraction of hertz $\mathrm{Hz}$ to high frequencies in rotor bar pass as several thousand Hz. Another proses for the transducers used in the vibration measurements were:

- Small output resistance transducers to convert the vibration signals to a voltage signal.

- A void the effect of the surface movement through small sensor mass.

- $\quad$ large frequency ranges $0.5 \mathrm{~Hz}$ to over $10 \mathrm{kHz}$. 
As shown in Figure 2 The Comm test Vb8 is a Four Channel Vibration Analysis System. To distinguish between unbalance types and solve unbalance faults, it's important to measure the Instantaneous Angular Speed IAS and relate it to shaft positions for calibration vibration frequencies, a laser tachometer is fitted. The Assent 2015 is the used software to accurate and efficient vibration data analysis.

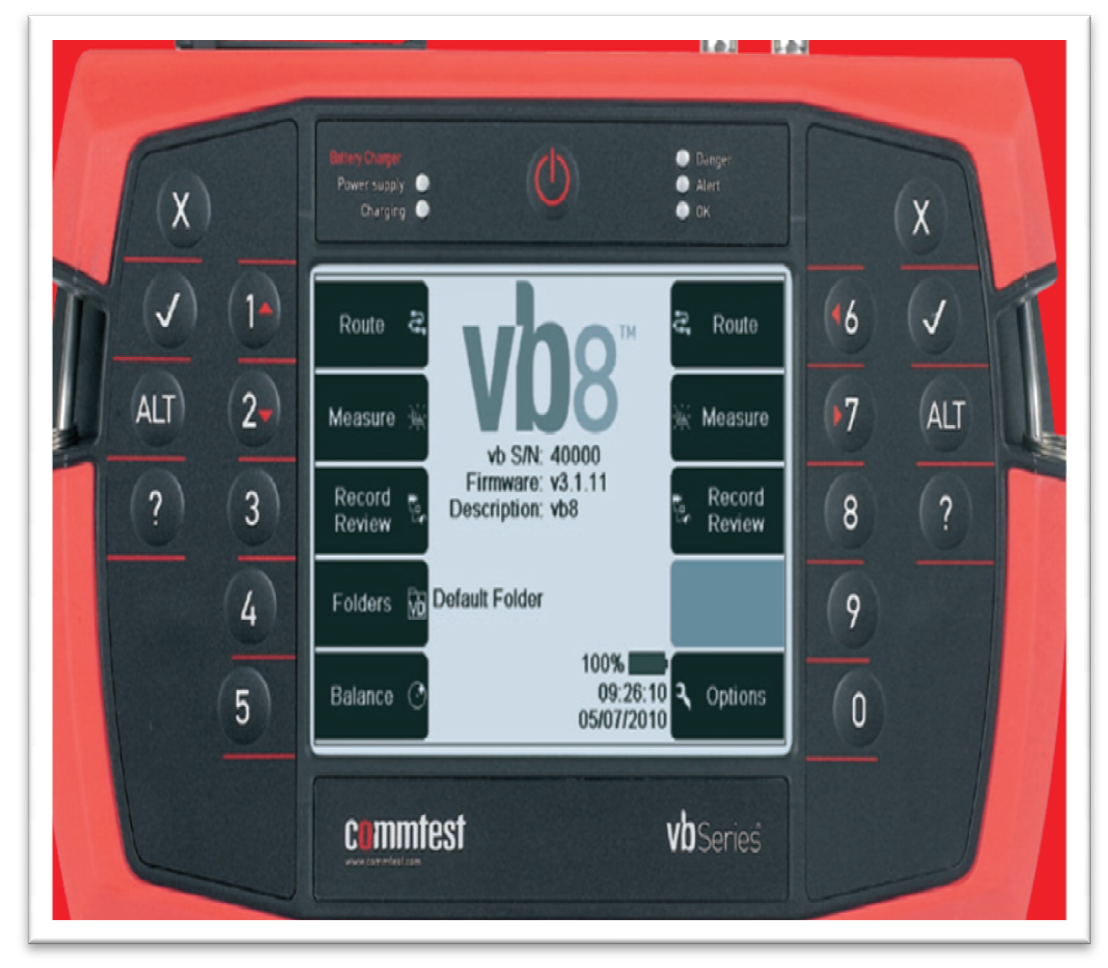

Figure 2: Comm Test Vibration Meter Device.

\section{Unbalance Identification}

The test rig arrangement is (intermediate rotor) the rotor system arrangement as following the disc is center mounted and supported by ball bearings. Various instruments were used to acquire the vibration data for example vibration accelerometers were used for identification process unbalance.

The unbalance conditions are 0,30, 40, $55 \mathrm{gm}$ unbalance each time on $2.5 \mathrm{~cm}$ from the center of the disc and disc width $8,12,16 \mathrm{~mm} .27$ set of data are collected in each case. The neural network preparation and validation were done by the practical data beside the confusion matrix which generated from four different unbalance situations: first from horizontal direction statistical features, second was vertical direction statistical features, third was the frequency spectrum in horizontal direction, and fourth was the frequency amplitude in vertical direction.

\section{Application of Neural Networks}

ANNs were suggested as they are non-parametric. Biological findings encourage the depicting of artificial neural networks the advantages of artificial neural networks in rotating machines automatic fault detection. The neuron is the basic building block of ANN. The model use the sum of M input values $\left(\mathrm{a}_{\mathrm{i}}\right)$ and a bias term $\left(\Theta_{\mathrm{N}}\right)$ to calculate the activation value $(x)$. The output signal (S) is a nonlinear function $f(x)$ of the activation value. The Neural network feed forward consists of two layers: 
- The data is treated and processed by the hidden layer

- The result of the analysis conducted by the output layer i.e. unbalance severity class.

The hidden layer processed the vibration data and the unbalance severity classification by output layer. The Figure 3describe a forward feed neural network.

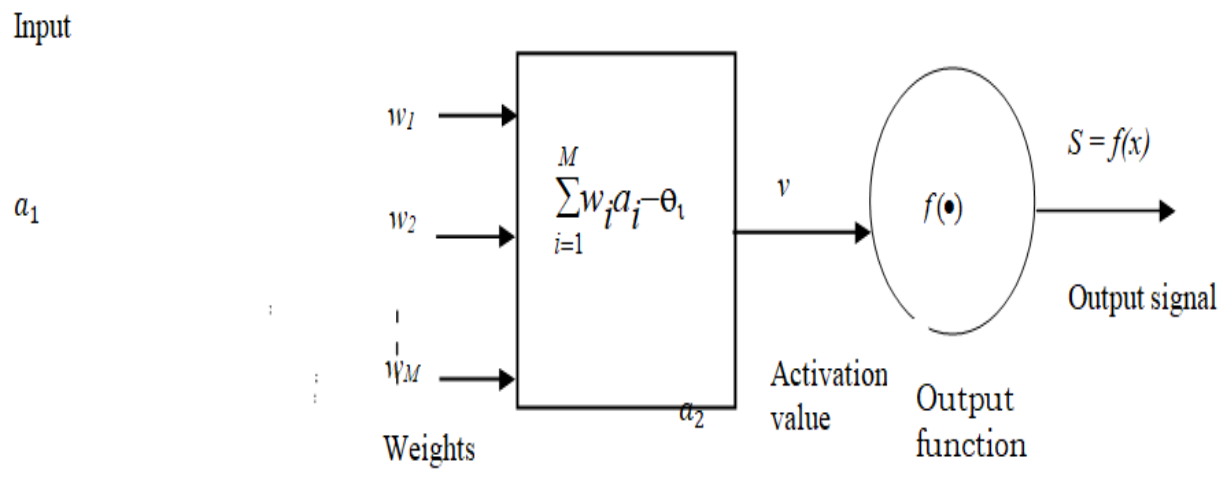

$a$

Figure 3: Typical Neuron Model.

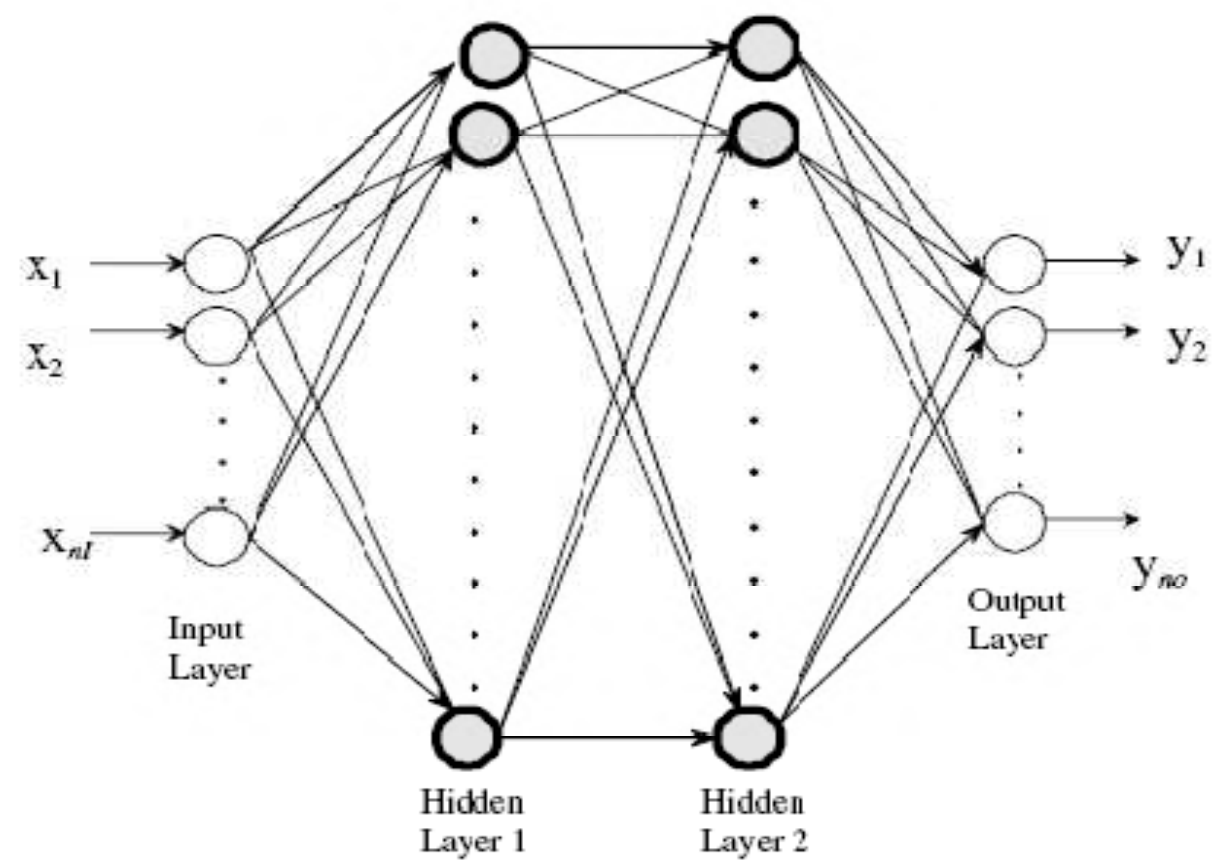

Figure 4: ANN Multi-Layered Feed Forward (Yiakopoulos C. T. 2011).

The arrangement of the ANN feed forward is described as input layer consists of 6 neurons. The activation function for tan sigmoidal function for both the hidden layers. The initial weights are chosen from randomly generated rational numbers between 0 to 1 . Gradient descendent method with momentum factor is used as learning algorithm for optimizing/updating the initial weights of neural network. 


\section{RESULTS AND DISCUSSIONS}

Using MATLAB calculate the ANN preparation and validation of faults. The confusion matrices considered the unbalance severities and classification using ANN. The experiments were conducted at different unbalances conditions such as zero unbalance, 30, 40, 55 grams added to the disc at $25 \mathrm{~mm}$ from the shaft center. Each case was considered classes like class 1 , 2, 3 and 4. The variation of statistical features and frequency domain amplitudes from the experimental data are collected in both directions vertical and horizontal. The system tested at $25 \mathrm{~Hz}(1500 \mathrm{rpm})$. In all the four cases the data is added to the neural network and confusion matrices.ANN preparation data are explained in Table 1 gives the statistical features at $30 \mathrm{gm}$ unbalance in horizontal direction. Table (2) gives the frequency domain amplitudes in horizontal direction at different amplitudes. Also, similar data for vertical direction have been derived. Features and frequency domain amplitude are used for training and testing of ANN. Displaying the results of the test as a two-dimensional confusion matrix and each class described in one row and one column.

Table 1: Statistical Features at 30 Gm Unbalance in Horizontal Direction

\begin{tabular}{|c|c|c|c|c|c|c|}
\hline S. No. & Mean (mm) & Rms (mm) & Variance $\left(\mathrm{mm}^{2}\right)$ & Std Deviation (mm) & Skewness & Kurtosis \\
\hline 1 & $2.94 \mathrm{E}-02$ & $4.12 \mathrm{E}-02$ & $6.46 \mathrm{E}-04$ & $2.89 \mathrm{E}-02$ & $2.94 \mathrm{E}-02$ & $4.12 \mathrm{E}-02$ \\
\hline 2 & $4.07 \mathrm{E}-02$ & $4.94 \mathrm{E}-02$ & $6.09 \mathrm{E}-04$ & $2.80 \mathrm{E}-02$ & $4.07 \mathrm{E}-02$ & $4.94 \mathrm{E}-02$ \\
\hline 3 & $2.90 \mathrm{E}-02$ & $4.03 \mathrm{E}-02$ & $6.09 \mathrm{E}-04$ & $2.80 \mathrm{E}-02$ & $2.90 \mathrm{E}-02$ & $4.03 \mathrm{E}-02$ \\
\hline 4 & $3.51 \mathrm{E}-02$ & $4.51 \mathrm{E}-02$ & $6.29 \mathrm{E}-04$ & $2.85 \mathrm{E}-02$ & $3.51 \mathrm{E}-02$ & $4.51 \mathrm{E}-02$ \\
\hline 5 & $3.83 \mathrm{E}-02$ & 4.77E-02 & $6.23 \mathrm{E}-04$ & $2.84 \mathrm{E}-02$ & $3.83 \mathrm{E}-02$ & $4.77 \mathrm{E}-02$ \\
\hline 6 & $3.83 \mathrm{E}-02$ & 4.78E-02 & $6.40 \mathrm{E}-04$ & $2.87 \mathrm{E}-02$ & $3.83 \mathrm{E}-02$ & 4.78E-02 \\
\hline 7 & $4.70 \mathrm{E}-02$ & $1.15 \mathrm{E}-01$ & $8.51 \mathrm{E}-03$ & $1.05 \mathrm{E}-01$ & $4.70 \mathrm{E}-02$ & $1.15 \mathrm{E}-01$ \\
\hline 8 & $5.63 \mathrm{E}-02$ & $1.65 \mathrm{E}-01$ & $1.87 \mathrm{E}-02$ & $1.55 \mathrm{E}-01$ & $5.63 \mathrm{E}-02$ & $1.65 \mathrm{E}-01$ \\
\hline 9 & $9.13 \mathrm{E}-02$ & $2.96 \mathrm{E}-01$ & $6.17 \mathrm{E}-02$ & $2.82 \mathrm{E}-01$ & $9.13 \mathrm{E}-02$ & $2.96 \mathrm{E}-01$ \\
\hline 10 & $6.05 \mathrm{E}-02$ & $2.00 \mathrm{E}-01$ & $2.81 \mathrm{E}-02$ & $1.90 \mathrm{E}-01$ & $6.05 \mathrm{E}-02$ & $2.00 \mathrm{E}-01$ \\
\hline 11 & $4.19 \mathrm{E}-02$ & $7.81 \mathrm{E}-02$ & $3.35 \mathrm{E}-03$ & $6.60 \mathrm{E}-02$ & $4.19 \mathrm{E}-02$ & $7.81 \mathrm{E}-02$ \\
\hline 12 & $4.07 \mathrm{E}-02$ & $1.73 \mathrm{E}-01$ & $2.20 \mathrm{E}-02$ & $1.68 \mathrm{E}-01$ & $4.07 \mathrm{E}-02$ & $1.73 \mathrm{E}-01$ \\
\hline 13 & $5.62 \mathrm{E}-02$ & $2.32 \mathrm{E}-01$ & $3.94 \mathrm{E}-02$ & $2.25 \mathrm{E}-01$ & $5.62 \mathrm{E}-02$ & 2.32E-01 \\
\hline 14 & $7.57 \mathrm{E}-02$ & $2.94 \mathrm{E}-01$ & $6.28 \mathrm{E}-02$ & $2.84 \mathrm{E}-01$ & $7.57 \mathrm{E}-02$ & $2.94 \mathrm{E}-01$ \\
\hline 15 & $6.42 \mathrm{E}-02$ & $1.56 \mathrm{E}-01$ & $1.57 \mathrm{E}-02$ & $1.42 \mathrm{E}-01$ & $6.42 \mathrm{E}-02$ & $1.56 \mathrm{E}-01$ \\
\hline 16 & $1.06 \mathrm{E}-01$ & $3.10 \mathrm{E}-01$ & $6.60 \mathrm{E}-02$ & $2.92 \mathrm{E}-01$ & $1.06 \mathrm{E}-01$ & $3.10 \mathrm{E}-01$ \\
\hline 17 & $1.21 \mathrm{E}-01$ & $3.60 \mathrm{E}-01$ & $8.91 \mathrm{E}-02$ & $3.39 \mathrm{E}-01$ & $1.21 \mathrm{E}-01$ & $3.60 \mathrm{E}-01$ \\
\hline 18 & $5.88 \mathrm{E}-02$ & $1.30 \mathrm{E}-01$ & $1.04 \mathrm{E}-02$ & $1.16 \mathrm{E}-01$ & $5.88 \mathrm{E}-02$ & $1.30 \mathrm{E}-01$ \\
\hline 19 & $6.43 \mathrm{E}-02$ & $1.68 \mathrm{E}-01$ & $1.88 \mathrm{E}-02$ & $1.56 \mathrm{E}-01$ & $6.43 \mathrm{E}-02$ & $1.68 \mathrm{E}-01$ \\
\hline 20 & $2.91 \mathrm{E}-02$ & $4.18 \mathrm{E}-02$ & $6.92 \mathrm{E}-04$ & $2.99 \mathrm{E}-02$ & $2.91 \mathrm{E}-02$ & 4.18E-02 \\
\hline
\end{tabular}


Table 2: The Spectrum at Different Unbalances in Horizontal Direction

\begin{tabular}{|c|c|c|c|c|}
\hline & Classl (Nil unbalance) & $\begin{array}{c}\text { Class2 } \\
25 \mathrm{mmm})\end{array}$ & $\begin{array}{c}\text { Class3 } 3(40 \mathrm{gm}) \text { unb. at } \\
25 \mathrm{~mm})\end{array}$ & $\begin{array}{l}\text { Class4 (55gm) unb } \\
\text { at } 25 \mathrm{~mm})\end{array}$ \\
\hline SNo. & FFT Amp & FFT Amp & FFT Amp & FFT Amp \\
\hline 1 & $2.67 \mathrm{E}-02$ & $7.86 \mathrm{E}-03$ & $722 \mathrm{E}-03$ & $1.71 \mathrm{E}-02$ \\
\hline 2 & $2.62 \mathrm{E}-02$ & $6.83 \mathrm{E}-03$ & $134 \mathrm{E}-02$ & $1.44 \mathrm{E}-02$ \\
\hline 3 & $2.75 \mathrm{E}-02$ & $7.48 \mathrm{E}-03$ & $1.03 \mathrm{E}-02$ & $1.47 \mathrm{E}-02$ \\
\hline 4 & $2.64 \mathrm{E}-02$ & $722 \mathrm{E}-03$ & $9.54 \mathrm{E}-03$ & $1.29 \mathrm{E}-02$ \\
\hline 5 & $2.60 \mathrm{E}-02$ & $6.06 \mathrm{E}-03$ & $8.64 E-03$ & $1.66 \mathrm{E}-02$ \\
\hline 6 & $2.22 \mathrm{E}-02$ & $6.32 \mathrm{E}-03$ & $1.10 \mathrm{E}-02$ & $1.17 \mathrm{E}-02$ \\
\hline$?$ & $233 \mathrm{E}-02$ & $7.09 \mathrm{E}-03$ & $1.10 \mathrm{E}-02$ & $1.22 \mathrm{E}-02$ \\
\hline 8 & $2.28 \mathrm{E}-02$ & $8.38 \mathrm{E}-03$ & $1.04 \mathrm{E}-02$ & $8.77 \mathrm{E}-03$ \\
\hline 9 & $2.19 \mathrm{E}-02$ & $696 \mathrm{E}-03$ & $9.15 \mathrm{E}-03$ & $9.80 \mathrm{E}-03$ \\
\hline 10 & $2.36 \mathrm{E}-02$ & $7.61 \mathrm{E}-03$ & $1.02 \mathrm{E}-02$ & $1.04 \mathrm{E}-02$ \\
\hline 11 & $32.29 \mathrm{E}-02$ & $799 \mathrm{E}-03$ & $1.01 \mathrm{E}-02$ & $1.19 \mathrm{E}-02$ \\
\hline 12 & $5.04 E-02$ & $7.61 \mathrm{E}-03$ & $9.67 \mathrm{E}-03$ & $1.22 \mathrm{E}-02$ \\
\hline 13 & $535 \mathrm{E}-02$ & $9.54 \mathrm{E}-03$ & $1.11 \mathrm{E}-02$ & $1.04 \mathrm{E}-02$ \\
\hline 14 & $4.43 \mathrm{E}-02$ & $1.13 \mathrm{E}-02$ & $1.06 \mathrm{E}-02$ & $1.22 \mathrm{E}-02$ \\
\hline 15 & $1.84 \mathrm{E}-02$ & $9.15 \mathrm{E}-03$ & $1.04 \mathrm{E}-02$ & $1.07 \mathrm{E}-02$ \\
\hline 16 & $5.74 \mathrm{E}-02$ & $1.13 \mathrm{E}-02$ & $1.04 \mathrm{E}-02$ & $1.08 \mathrm{E}-02$ \\
\hline 17 & $3.69 \mathrm{E}-02$ & $1.28 \mathrm{E}-02$ & $1.02 \mathrm{E}-02$ & $1.02 \mathrm{E}-02$ \\
\hline 18 & $3.70 \mathrm{E}-02$ & $9.15 \mathrm{E}-03$ & $1.08 \mathrm{E}-02$ & $1.10 \mathrm{E}-02$ \\
\hline 19 & $3.22 \mathrm{E}-02$ & $9.28 \mathrm{E}-03$ & $1.07 \mathrm{E}-02$ & $1.43 \mathrm{E}-02$ \\
\hline 20 & $7.76 \mathrm{E}-02$ & $1.03 \mathrm{E}-02$ & $1.10 \mathrm{E}-02$ & $1.04 \mathrm{E}-02$ \\
\hline
\end{tabular}

Figure 5 shows the confusion matrix related to the horizontal direction statistical features at the same time figure 6represent the vertical direction statistics. Figure 5 and Figure 6 are the confusion matrices of the vibration amplitude in horizontal and vertical direction. The ANN predict the unbalance for practical at $30 \mathrm{gm}$ unbalance, $40 \mathrm{gm}$ unbalance and $55 \mathrm{gm}$ unbalance in vertical direction. The statistical features introduce better results than frequency domain amplitude and achieve accuracy $93.8 \%$ which is better than horizontal direction. At rotor speed $1500 \mathrm{rpm}$ the vibration responses are shown in Figure9 and figure 10. The characteristic of signal unbalance is high amplitude at 1x component in spectrum. The $1 \mathrm{x}$ of the horizontal readings is not the dominant component if compared with the $2 \mathrm{x}$ amplitude as shown in Figure 11 and Figure 12. There are many other vibration faults can cause the presence of $2 \mathrm{x}$ component so the results of ANN horizontal considered not accurate. The versus appears in vertical directions the $1 \mathrm{x}$ components is dominated, hence the results of Neural Networks more accurate. The classification accuracy achieved in the proposed method in unbalance case has $93.8 \%$. 


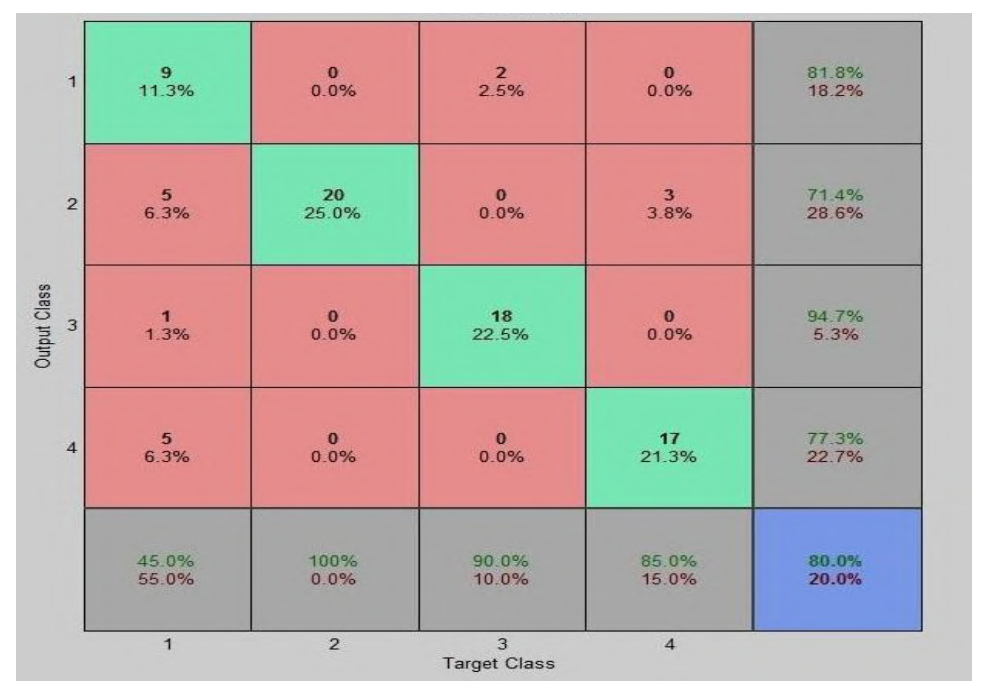

Figure 5: Statistical Confusion Matrix in Horizontal.

\begin{tabular}{|c|c|c|c|c|c|}
\hline \multirow{3}{*}{ 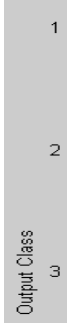 } & $\begin{array}{c}17 \\
21.3 \%\end{array}$ & $\begin{array}{c}\mathbf{0} \\
0.0 \%\end{array}$ & $\begin{array}{c}\mathbf{0} \\
0.0 \%\end{array}$ & $\begin{array}{c}\mathbf{0} \\
0.0 \%\end{array}$ & $\begin{array}{l}100 \% \\
0.0 \%\end{array}$ \\
\hline & $1.3 \%$ & $\begin{array}{c}20 \\
25.0 \%\end{array}$ & $\begin{array}{l}\mathbf{0} \\
0.0 \%\end{array}$ & $2.5 \%$ & $\begin{array}{l}87.0 \% \\
13.0 \%\end{array}$ \\
\hline & $2.5 \%$ & \begin{tabular}{c}
$\mathbf{0}$ \\
\hdashline $.0 \%$
\end{tabular} & $\begin{array}{c}20 \\
25.0 \%\end{array}$ & $\begin{array}{c}\mathbf{0} \\
0.0 \%\end{array}$ & $\begin{array}{r}90.9 \% \\
9.1 \%\end{array}$ \\
\hline \multirow[t]{3}{*}{4} & $\stackrel{0}{0} \%$ & $\begin{array}{c}\mathbf{0} \\
0.0 \%\end{array}$ & $\begin{array}{c}\mathbf{0} \\
0.0 \%\end{array}$ & $\begin{array}{c}18 \\
22.5 \%\end{array}$ & $\begin{array}{l}100 \% \\
0.0 \%\end{array}$ \\
\hline & $\begin{array}{l}85.0 \% \\
15.0 \%\end{array}$ & $\begin{array}{l}100 \% \\
0.0 \%\end{array}$ & $\begin{array}{l}100 \% \\
0.0 \%\end{array}$ & $\begin{array}{l}90.0 \% \\
10.0 \%\end{array}$ & $\begin{array}{l}93.8 \% \\
6.3 \%\end{array}$ \\
\hline & 1 & 2 & ${ }^{3}$ & 4 & \\
\hline
\end{tabular}

Figure 6: Statistical Confusion Matrix in Vertical.

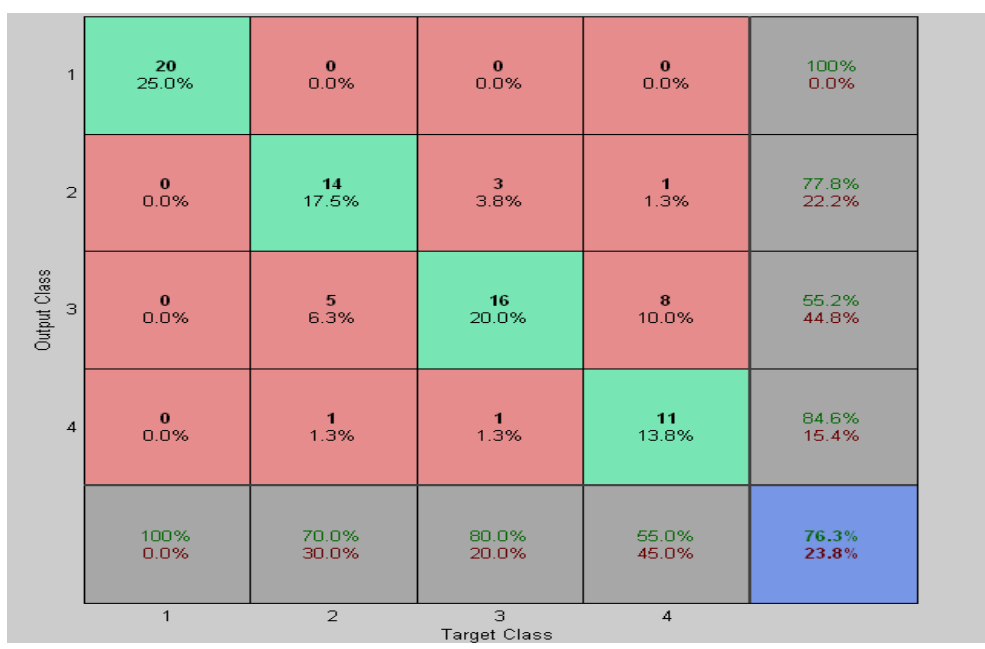

Figure 7: Frequency Amplitude Confusion Matrix in Horizontal. 


\begin{tabular}{|c|c|c|c|c|c|}
\hline 1 & $\begin{array}{c}\mathbf{8} \\
10.0 \%\end{array}$ & $1 . \mathbf{3} \%$ & $2.5 \%$ & $\stackrel{\mathbf{0}}{\circ .0 \%}$ & $\begin{array}{l}72.7 \% \\
27.3 \%\end{array}$ \\
\hline 2 & $\begin{array}{c}\mathbf{8} \\
10.0 \%\end{array}$ & $21.3 \%$ & 3.8\% & $\begin{array}{l}\mathbf{0} \\
0.0 \%\end{array}$ & $\begin{array}{l}60.7 \% \\
39.3 \%\end{array}$ \\
\hline & $5.0 \%$ & ०.0\% & $\begin{array}{c}14 \\
17.5 \%\end{array}$ & \begin{tabular}{l}
$\mathbf{0}$ \\
\hdashline $.0 \%$
\end{tabular} & $\begin{array}{l}77.8 \% \\
22.2 \%\end{array}$ \\
\hline 4 & $\begin{array}{l}\mathbf{0} \\
0.0 \%\end{array}$ & $2.5 \%$ & $1.3 \%$ & $\begin{array}{c}20 \\
25.0 \%\end{array}$ & $\begin{array}{l}87.0 \% \\
13.0 \%\end{array}$ \\
\hline & $\begin{array}{l}40.0 \% \\
60.0 \%\end{array}$ & $\begin{array}{l}85.0 \% \\
15.0 \%\end{array}$ & $\begin{array}{l}70.0 \% \\
30.0 \%\end{array}$ & $\begin{array}{l}100 \% \\
0.0 \%\end{array}$ & $\begin{array}{l}73.8 \% \\
26.2 \%\end{array}$ \\
\hline
\end{tabular}

Figure 8: Frequency Amplitude Confusion Matrix in Vertical.

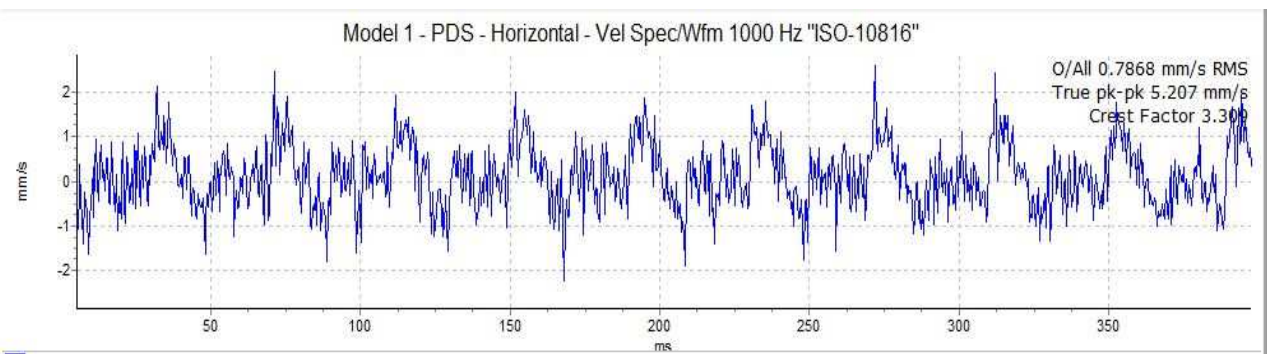

a. Balanced.

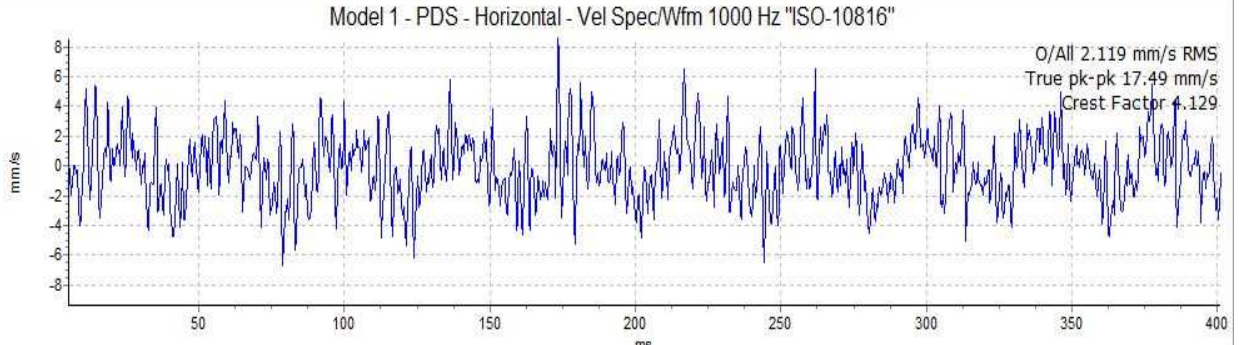

b. $30 \mathrm{gm}$ Unbalance.

Model 1 - PDS - Horizontal - Vel Spec/Wfm 1000 Hz "ISO-10816"

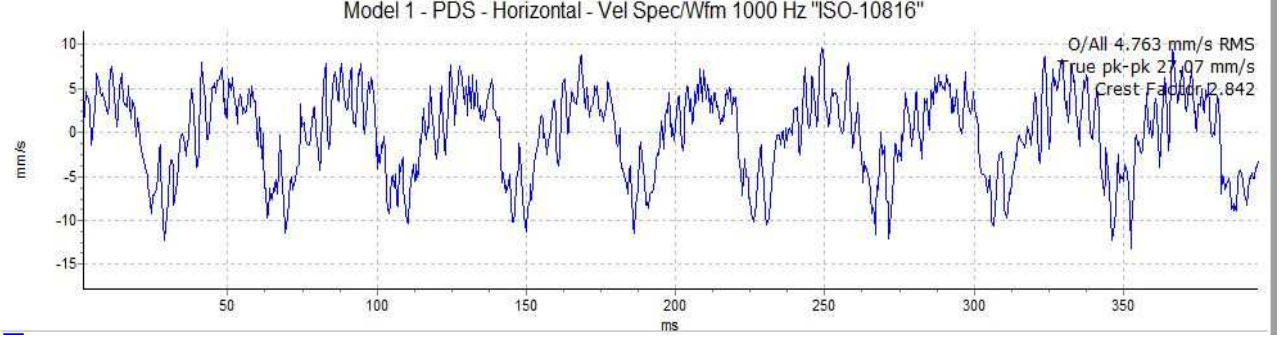

c. 40 gm Unbalance.

Model 1 - PDS - Horizontal - Vel Spec/Wfm 1000 Hz "ISO-10816"

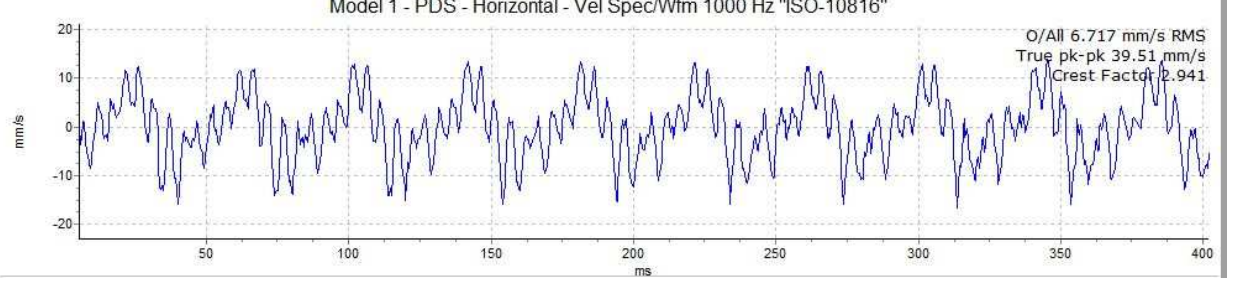

d. 55 gm Unbalance.

Figure 9: Time Domain Vibration Signals Horizontal Response at $25 \mathrm{~Hz}$. 


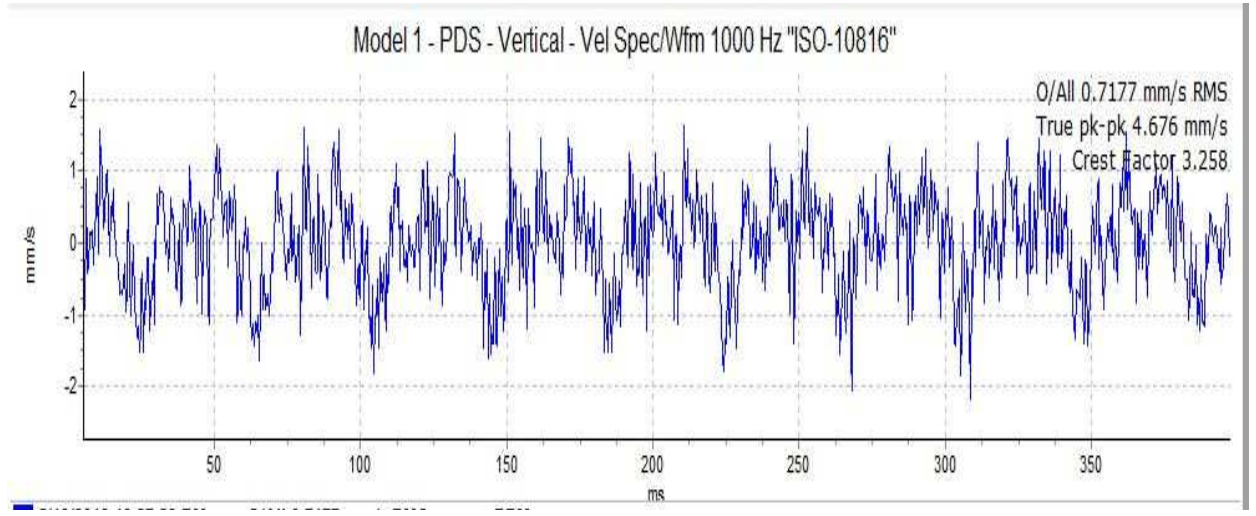

a. Balanced.

Model 1 - PDS - Vertical - Vel SpecWfm $1000 \mathrm{~Hz}$ "ISO-10816"

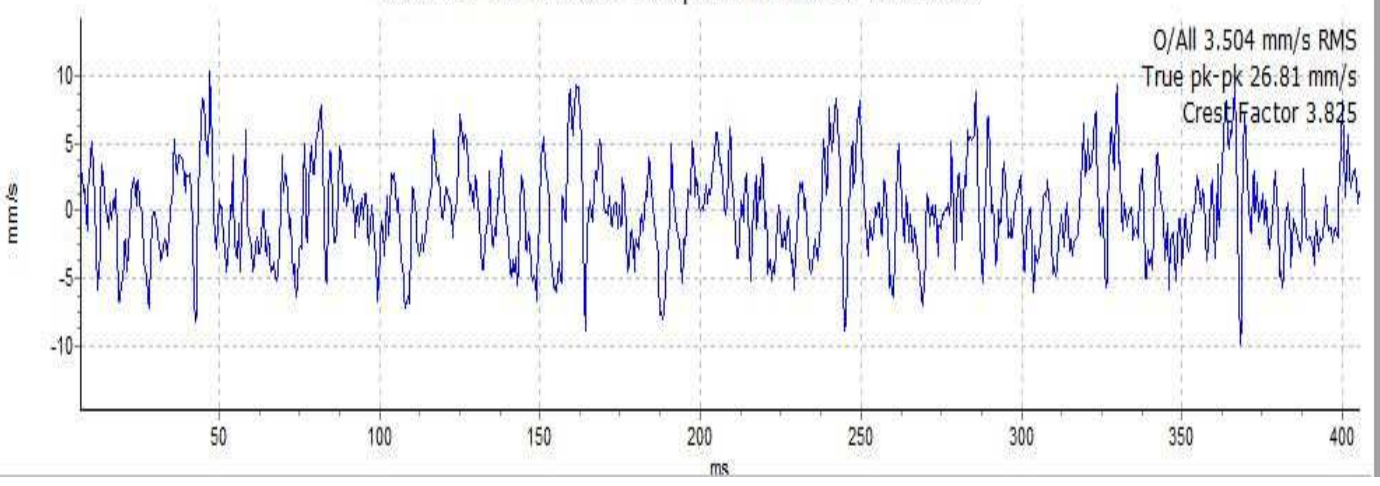

b. 30 gm Unbalance.

Model 1 - PDS - Vertical - Vel SpecWfm $1000 \mathrm{~Hz}$ "ISO-10816"

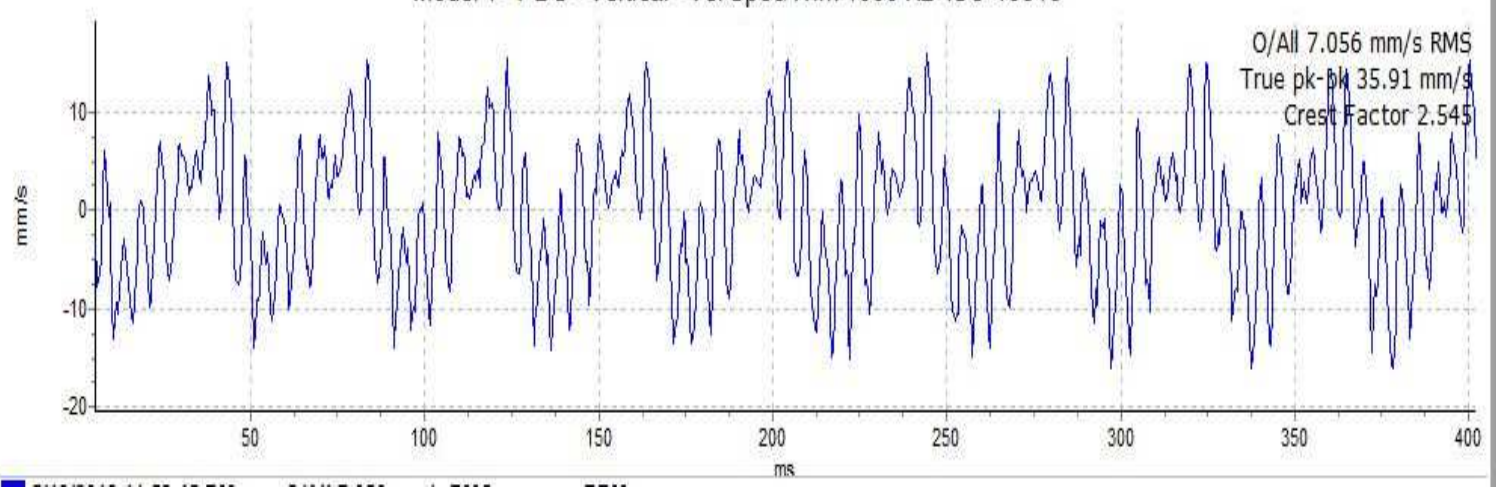

c. $40 \mathrm{gm}$ Unbalance.

Model 1 - PDS - Vertical - Vel SpecWfm 1000 Hz "ISO-10816"

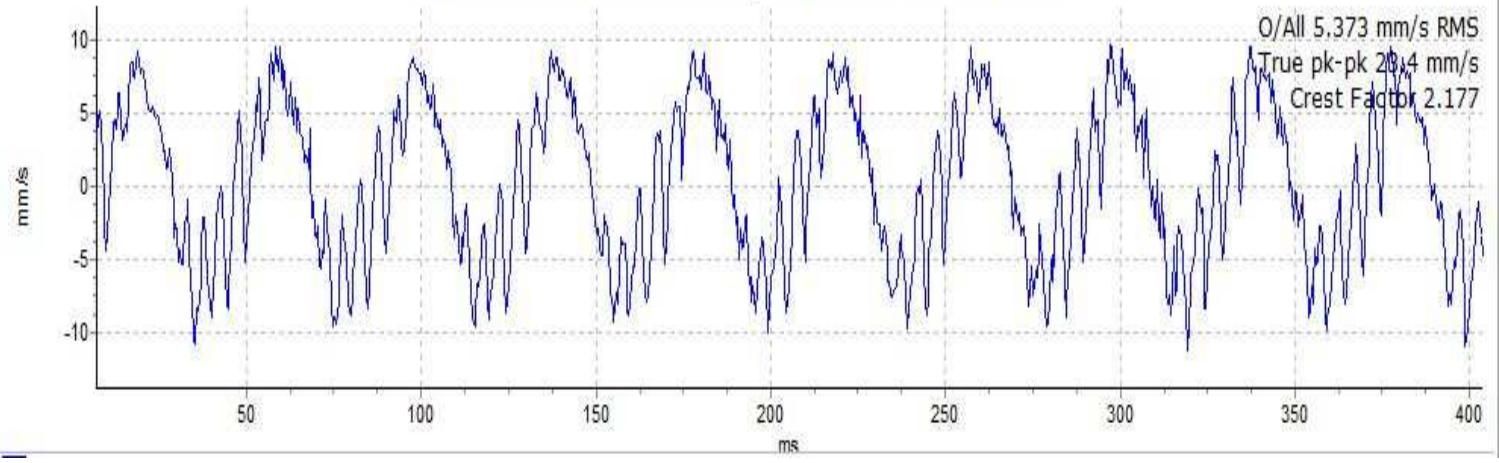

d. 55 gm Unbalance.

Figure 10: Time Domain Vibration Signals Vertical Response at 1500 Rpm (25Hz). 


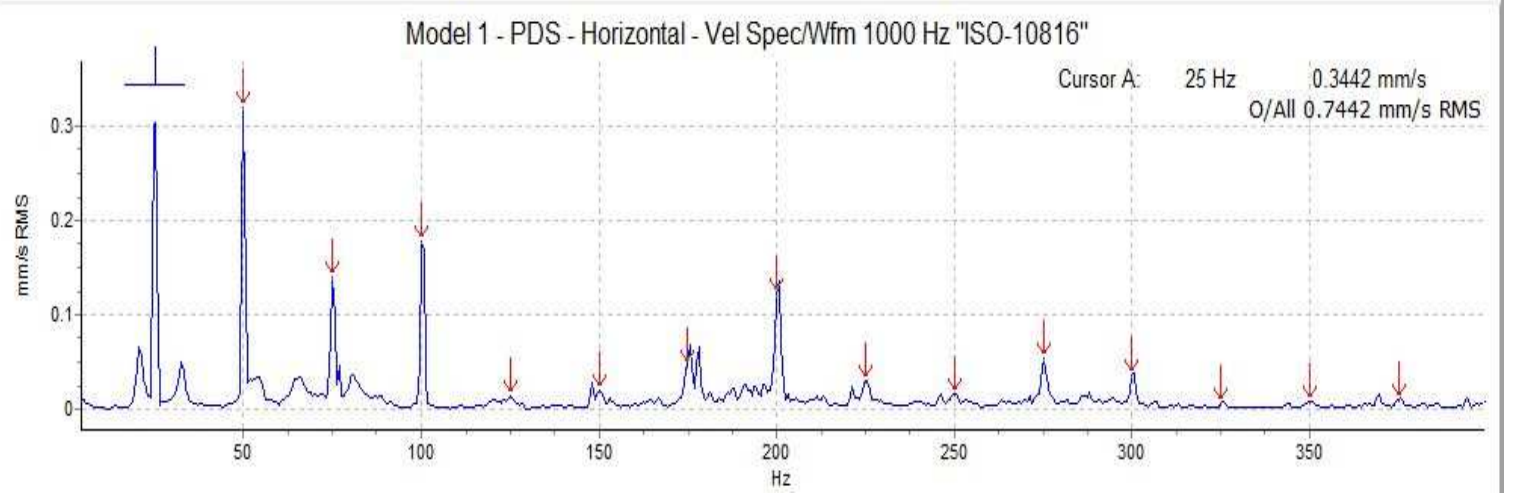

a. Balanced.

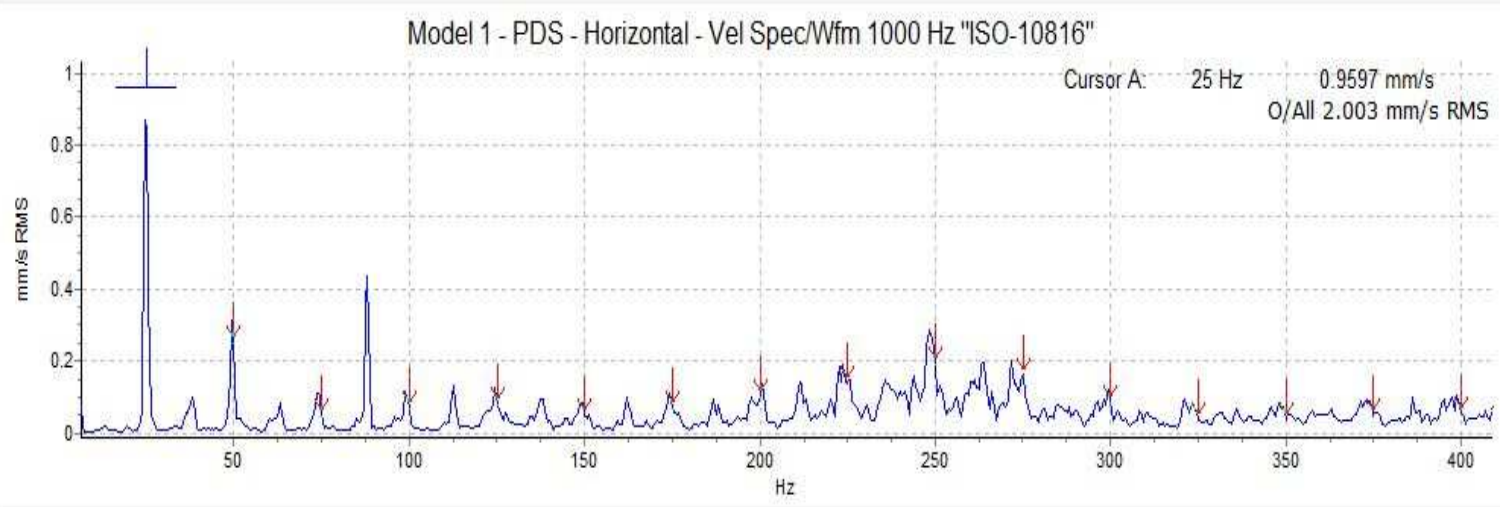

b. 30 gm Unbalance.

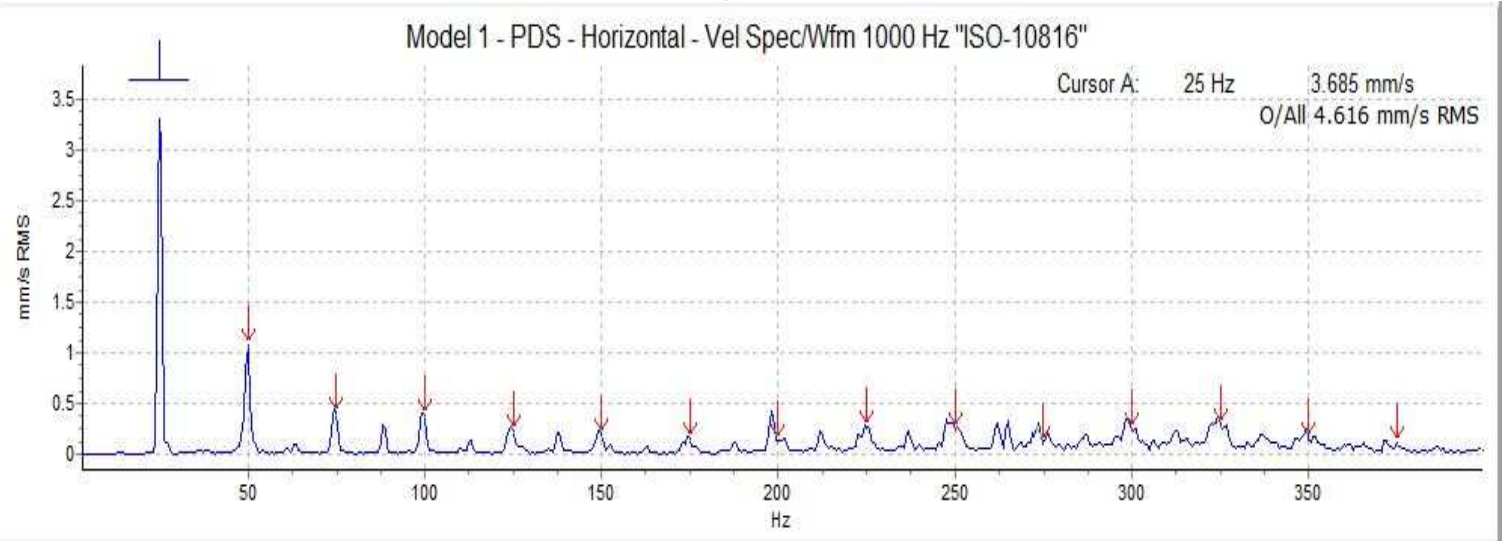

c. 40 gm Unbalance.

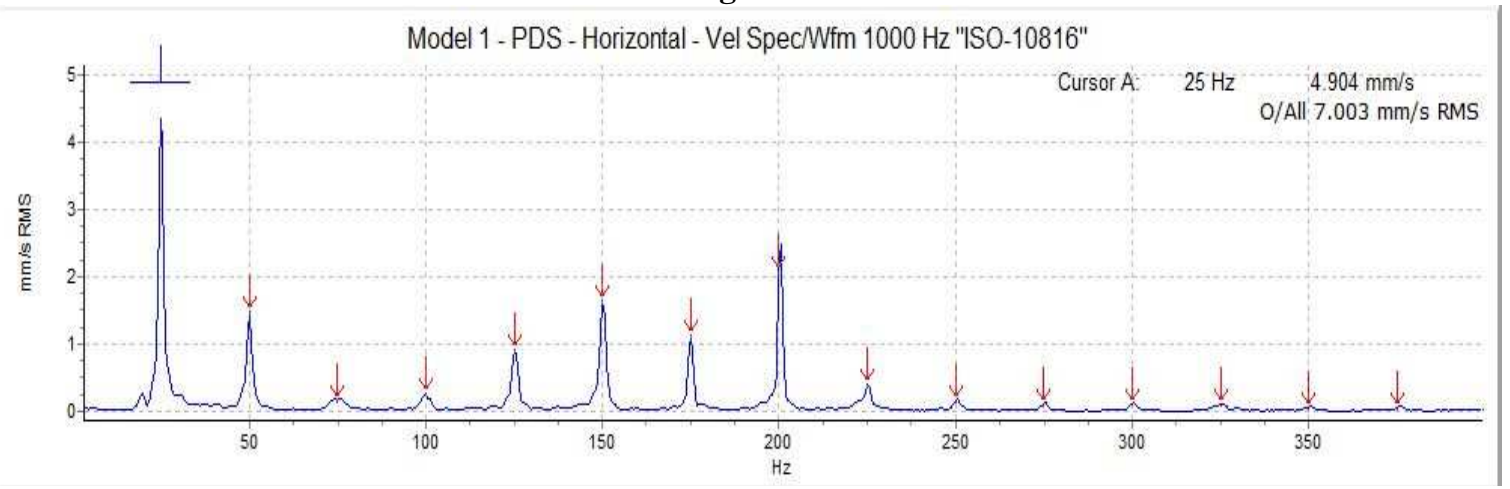

d. $55 \mathrm{gm}$ Unbalance.

Figure 11: FFT Plots for various Horizontal at $25 \mathrm{~Hz}$. 


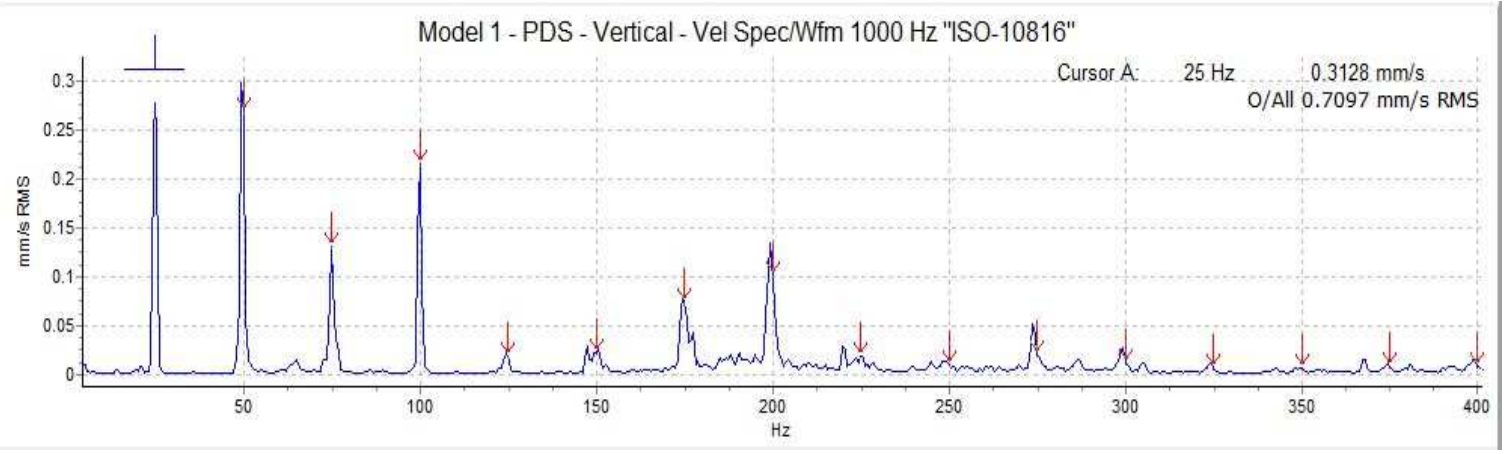

a. Balanced.

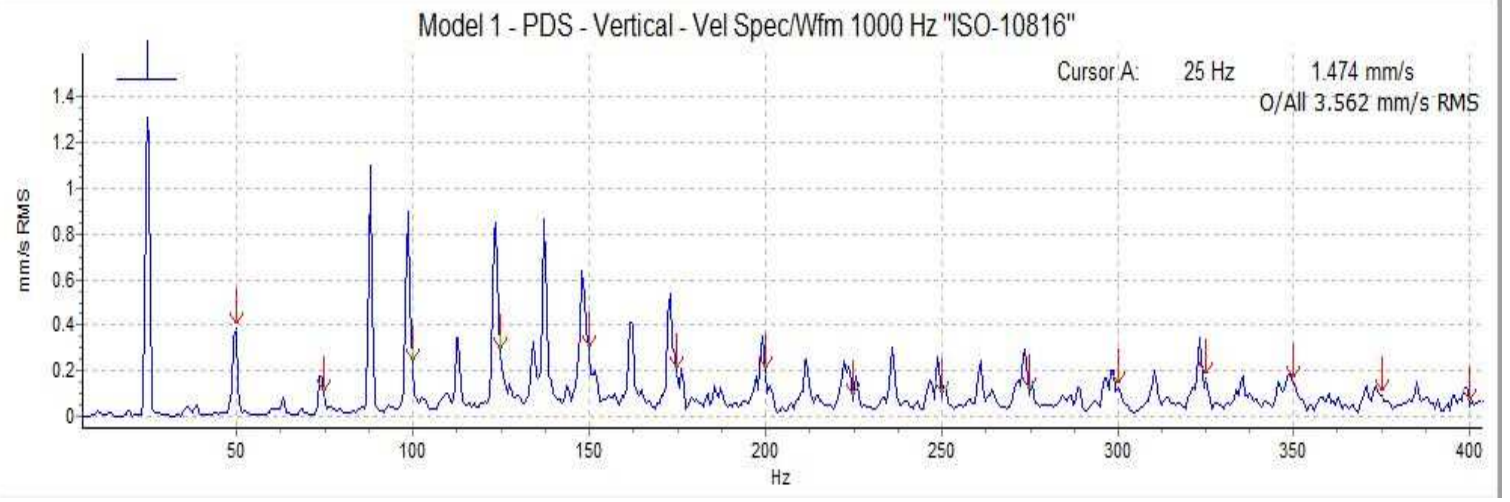

b. 30 gm Unbalance.

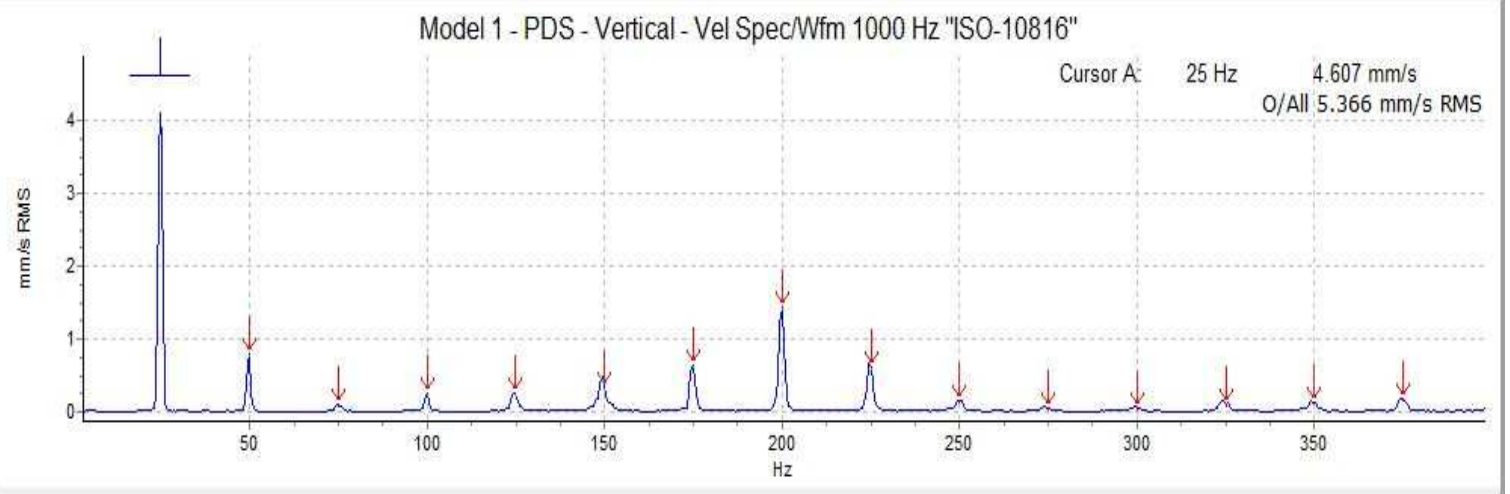

c. $40 \mathrm{gm}$ Unbalance.

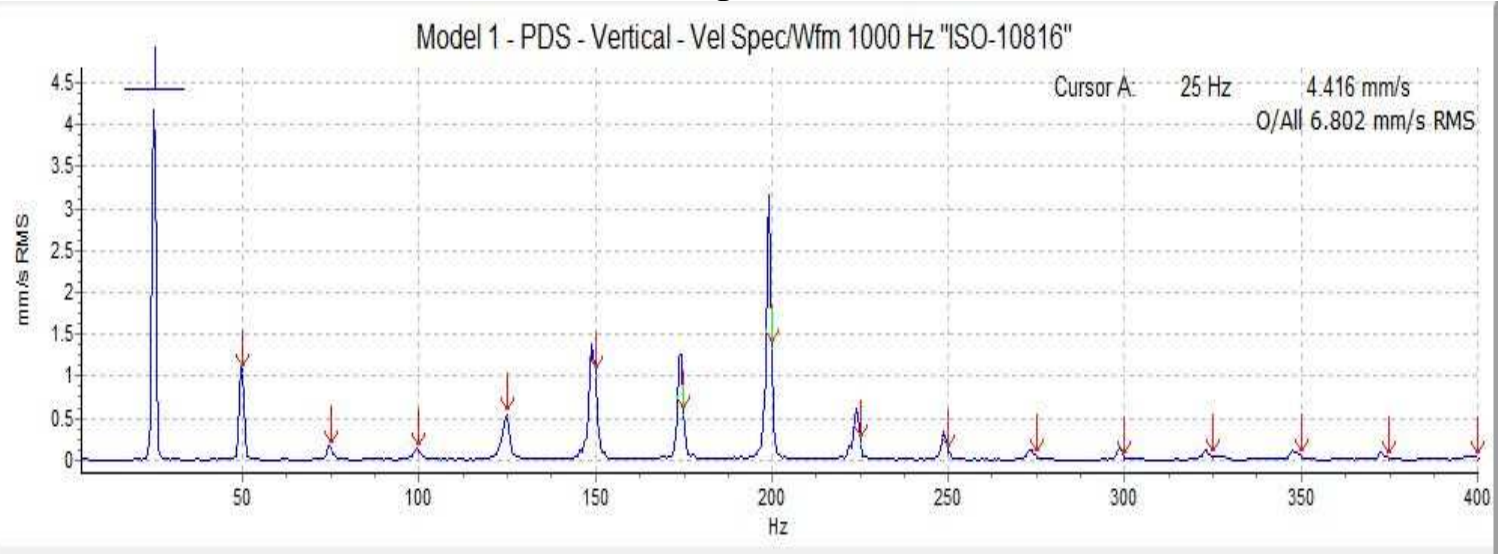

d. 55 gm Unbalance.

e. Figure 12: FFT Plots for Various Vertical at $25 \mathrm{~Hz}$. 


\section{CONCLUSIONS}

The results of using ANN in unbalance severity evaluation of experiments are conducted to simulating different unbalance conditions. Statistical features are extracted from the vibration signals obtained and generate the ANN cases. Both the ANNs cases are prepared and validated in horizontal and vertical measurement. The data classification occurs by modeling the neural network to classify the severity. The statistical features output is better than frequency domain amplitudes. In the same manner the vertical direction readings shows higher accuracy than classification output in horizontal direction vibration measurements. The method will support the decision-making process related to unbalance problem severity. The developed ANN gives the highest accuracy in unbalance identification and evaluation reaches to $93.8 \%$ precision.

\section{REFERENCES}

1. Ahmed A. Ibraheem, Nouby M. Ghazaly, G. T. Abd el-Jaber"Experimental Investigation for Single Plan Balancing Impellers between Bearings Using Frequency Response Function”International Journal of Control and Automation, Vol. 13, No. 1s, (2020), pp. 121-136.

2. Chen, D. and Wang, W. J. 2002. "Classification of wavelet patterns using multilayer neural networks." Mechanical Systems and Signal Processing 16 (4), 1: 695-704.

3. D., Genta G. and Bona F. 1989. "Unbalance response of rotors: a modal approach with some extensions to damped natural systems." Journal of Sound and Vibration 129-153.

4. Kalkat M., Yildirim S., and Uzmay I. 2005. "Design of artificial neural networks for rotor dynamics analysis of rotating machine systems." Mechatronics 15 1: 573-588.

5. Kankar P. K., Satish C. S., and Harsha, S. P. 2014. "Fault diagnosis of ball bearings using machine learning methods." Expert Systems with Applications 38, 1: 1876-1886.

6. Lei Y., He Z., and Zi Y. 2008. "A new approach to intelligent fault diagnosis of rotating machinery." Expert Systems with Applications 1593-1600.

7. Li, B., Mo-Yuen and James C. H. 2000. "Neural network-based motor rolling bearing fault diagnosis." IEEE Transaction on Industrial Electronics 47 (5), 1: 1060-1069.

8. S., Sekhar A. 2005. "Identification of Unbalance and Crack Acting Simultaneously in a Rotor System: Modal Expansion versus Reduced Basis Dynamic Expansion." Journal of Vibration and Control 11 (9) 1125-1145.

9. Sanz J., Perera R., and Huerta C. 2007. " Fault diagnosis of rotating machinery based on auto-associative neural networks and wavelet transforms." Journal of Sound and Vibration 302, 1: 981-999.

10. Sinha J. K. and Elbhbah, K. 2012. A future possibility of vibration-based condition monitoring of rotating machines. may 17. https://doi.org/10.1016/j.ymssp.2012.07.001.

11. Taplak, H., Erkaya, S., and Uzmay, I. 2012. Experimental analysis on fault detection for a direct coupled rotor-bearing system. may 12. https://doi.org/10.1016/j.measurement.2012.07.005.

12. Wang C. C., Kang Y., Shen P. C., Chang Y. P., and Chung Y. L. 2010. "Applications of fault diagnosis in rotating machinery by using time series analysis with neural network." Expert Systems with Applications 37, 1696-1702.

13. Yiakopoulos C. T., Gryllias K. C., and Antoniadis I. A. 2011. "Rolling element bearing fault detection in industrial environments based on a K-means clustering approach." Expert Systems with Applications 38, 2888-2911. 
